\title{
Exploration of functional health, mental well-being and cross-sex hormone use in a sample of Thai male-to-female transgendered persons (kathoeys)
}

\author{
Louis J Gooren ${ }^{1,2}$, Tanapong Sungkaew ${ }^{2}$ and Erik J Giltay ${ }^{3}$
}

Transgender people sometimes use cross-sex hormones without medical supervision. The use of cross-sex hormones, as well as the functional health and mental well-being, among male-to-female transgendered people ('kathoeys') in Chiang Mai, Thailand, was studied. Sixty kathoeys were interviewed regarding their use of cross-sex hormones and their family relationships. Individuals also completed the Life Orientation Test Revised (LOT-R) to assess dispositional optimism, the Social Functioning Questionnaire (SFQ) and the Short Form Health Survey 36 (SF-36). Three categories were established as follows: those who never cross-dress, those who sometimes cross-dress and those who always cross-dress in public. Of the 60 subjects, 44 had used hormones for prolonged periods ( $9.7 \pm 6.1$ years). Their use was related to the permanence of cross-dressing but unrelated to functional health and mental well-being. Fifty percent of subjects had overdosed on commonly used oral contraceptives. Three people used injectable oestrogen in a higher-than-recommended dose.

Self-acceptance was high or reasonably good $(83 \%)$ compared to no acceptance $(17 \%)$, and neither was related to the permanence of cross-dressing. Their acceptance by parents and siblings was also relatively high ( $85 \%$ and $89 \%$, respectively). The permanence of cross-dressing had no effect on the scores of optimism, SF-36 scores and social functioning. Acceptance by oneself or one's parents did not seem to affect most aspects of functional health and mental well-being, but non-acceptance by siblings generated lower scores on the social functioning and general mental health subscales. Stressors tended to include physical rather than social factors. In conclusion, the unsupervised use of cross-sex hormones was common among kathoeys, and $50 \%$ of the sample had overdosed on them. Acceptance was relatively good, except by siblings. New strategies are needed for a more responsible use of cross-sex hormones. Asian Journal of Andrology (2013) 15, 280-285; doi:10.1038/aja.2012.139; published online 28 January 2013

Keywords: cross-sex hormones; functional health; kathoeys; optimism; transgender; well-being

\section{INTRODUCTION}

Gender identity is the sense one has of being male or female. When a significant incongruence exists between gender identity and physical phenotype, this is defined as transgenderism. Some transgendered people desire to undergo phenotypical transition to the self-identified gender by means of hormonal and surgical treatment. ' 'Kathoey' is a Thai term for transgendered people that in the present time desire to be seen as women. ${ }^{2-4}$

Increasingly, the medical treatment of transgendered people is becoming a legitimate part of medicine endorsed by professional societies. ${ }^{5}$ Guidelines for hormone administration have been formulated by the Endocrine Society. ${ }^{5}$ When provided by a knowledgeable physician, such treatment is acceptably safe. ${ }^{5-7}$ However, the use of crosssex hormones without medical supervision of contra-indications and potential complications has become widespread, possibly because the hormonal preparations used for cross-sex hormone administration are readily available in Thailand. The latter may also have to do with the availability and expense of medical services for transsexual people, as well as the accessibility of such services. Little substantiated information exists on the magnitude and scope of the use of cross-sex hormones without medical supervision, and these data are often mentioned in the context of other types of studies, such as those on the use of illicit drugs and HIV prevention. ${ }^{8,9}$ There is one study that refers to the widespread use of hormones among transgendered people in Thailand, ${ }^{3}$ but so far there has been no other study that provides details on what hormones are used, how they are used or what dosages are used. While Thailand has very high standards for sex reassignment surgery ${ }^{10}$ and follows the recommendations of the World Professional Association for Transgender Health (http:// www.wpath.org/journal/www.iiav.nl/ezines/web/IJT/97-03/numbers/ symposion/ijtvo06no01_04.htm), there are no publicly known established services (for instance, by self-profiling or by membership of World Professional Association for Transgender Health) for hormonal treatment. It is of note that there are no significant barriers to obtain health care for the people of Thailand.

On the surface, Thai society seems to be characterized by a broad tolerance of the expression of transgender behaviour in public; this broad tolerance has also been documented by studies. ${ }^{11,12}$ 
This study is a feasibility study. It was a priori difficult to determine whether we could access sufficient subjects for inclusion and whether these subjects would be ready to be interviewed. However, one of this paper's authors (TS) had access to a sample of kathoeys through a personal acquaintance in Thailand's second city of Chiang Mai and, therefore, that location was chosen for this study. The first aim of this study was to make an inventory of the non-supervised use of cross-sex hormones among kathoeys.

The second aim was to assess functional health and mental wellbeing of kathoeys, as well as to verify whether the perceived Thai societal tolerance of kathoeys translates into individual mental wellbeing within the group concerned. It was also tested whether the degree of cross-dressing behaviour, acceptance by self and family and use of cross-sex hormones affected functional health and mental well-being.

It was also asked whether there were other members of the family (related by blood) who were transgendered or gay.

\section{SUBJECTS AND METHODS}

\section{Definition of the study population}

For the purpose of this project, subjects were approached who selfidentified as kathoeys. We included those subjects who had been living as kathoeys for at least 5 years, associating with other people in the same situation and, if using hormones, continuously using cross-sex hormones for at least 2 years.

\section{Method of data collection and subjects}

Interviews with kathoeys were conducted by one of the authors (TS), a native speaker of Thai. Subjects were recruited through word of mouth within a community of kathoeys. About $80 \%$ were students at two schools (a college level of education) and belonged to clubs of kathoeys informally connected with those schools. The remaining $20 \%$ were former students still connected with these clubs. The interviewees were all permanent residents of the city of Chiang Mai in Northern Thailand. Interviews were conducted at the homes of the interviewees or their friends' homes between mid-April 2012 and mid-June 2012 over a period of 10 weeks. The subjects received 200 baht (US\$ 7) compensation for their time spent on the interview, and their answers were noted by TS. In total, 60 subjects were interviewed.

\section{Ethics}

The purpose of the investigation was explained to the participants, each of whom consented, and the research was approved by the Ethical Review Board of the Androconsult Research Group, Chiang Mai, Thailand.

\section{Data collected}

In a self-designed questionnaire, subjects were asked about the initial age of onset of their transgender feelings, the period of time in which they had been living as a kathoey, their hormone use, their procurement of hormones and their level of satisfaction with the effects of hormones. Moreover, they described whether they had noted side effects of the use of hormones, whether they desired to undergo feminizing surgery and whether they were in fact seriously considering such surgery. Other questions concerned self-acceptance as kathoey, acceptance from and further relationships with their families and the existence of more transgendered or gay persons in their families (brothers, sisters, parents, uncles, aunts and cousins). In addition, their functional health and mental well-being were assessed with the Life Orientation Test Revised (LOT-R), Social Functioning
Questionnaire (SFQ) and the Short Form Health Survey 36 (SF-36). Dispositional optimism was assessed using the Life LOT-R, ${ }^{13}$ a 10 item self-reporting scale. The LOT-R total score ranges from 0 to 24 , with higher scores being indicative of a higher level of optimism. The scoring method for the LOT-R used in this study is the one described by the designers of the LOT-R. ${ }^{13}$ While some ${ }^{14}$ have argued for scoring separately the positive items of the LOT-R as signs of optimism and the negative items as signs of pessimism, this approach has been a matter of debate both on theoretical and psychometric grounds. It is defensible to use the LOT-R as it was originally designed and as it has been used in a large number of studies investigating optimism. The SFQ is an eight-item self-reported scale developed from the Social Functioning Schedule. ${ }^{15}$ The SFQ total score ranges from 0 to 24, with summed scores of 10 or more being indicative of a poorer-perceived social functioning. The SF-36 is a generic measure of different aspects of functional health and mental well-being derived from the Rand Medical Outcome Study. ${ }^{16}$ The SF-36 is a 36-item selfreported scale encompassing eight dimensions: bodily pain, role limitations due to physical health problems (role-physical), physical functioning, social functioning, general mental health (mental health), role limitations due to emotional problems (role-emotional), vitality and general health perceptions (general health). Scores range from 0 through 100, with higher scores indicating a better quality of life. Analyses were adjusted for age, which might be a confounder, as increasing age is an important determinant of (decreasing) optimism; health-related functioning; and mental well-being, as measured by the SF-36. For example, the normative values of several subscales (especially bodily pain, role-physical, physical functioning and general health) of the SF-36 decline with increasing age. ${ }^{17}$ These questionnaires have not been validated for use in the Thai language. Nevertheless, we have chosen these evaluations, as their reliability and validity have been well documented in the English language. All items on the questionnaires were orally presented to the interviewees by the interviewer (TS) and, if necessary, orally explained for comprehension.

\section{Statistical analysis}

Characteristics are summarized using descriptive statistics, with categorical variables presented as numbers and proportions and continuous data presented as mean \pm standard deviation (s.d.). Data were also presented according to three categories of transgender behaviour (i.e., no cross-dressing in public, sometimes cross-dressing and always cross-dressing) and two categories of cross-sex hormone use, with $P$-values assessed through analysis of variance (for linear trends), $t$ test for independent samples or chi-squared tests (linear-by-linear trend), when appropriate. The effects of self-acceptance, acceptance by parents and acceptance by brothers and sisters were tested by linear regression analysis and adjusted for age. Data are presented as mean \pm s.d., numbers (percentage) and standardized beta coefficients with accompanying $P$-values. All tests were two-tailed with $P<0.05$ denoting statistical significance. The software used was SPSS version 19.0 (SPSS Inc., Chicago, IL, USA).

\section{RESULTS}

\section{Hormone use}

Of the group of 60 self-labelled kathoeys, 44 were using hormones, while 16 were not (Table 1 ). The more permanently a subject was living in the female role, the more likely hormone use was. The overall group had been living the life of a kathoey for a prolonged period (13.9 \pm 7.3 years on average). Cross-sex hormones had also been used 
Table 1 Characteristics of a sample of kathoeys in Thailand based on their patterns of cross-dressing

\begin{tabular}{|c|c|c|c|c|c|c|}
\hline & No. & $\begin{array}{l}\text { All subjects } \\
\quad(n=60)\end{array}$ & $\begin{array}{l}\text { No cross-dressing in } \\
\text { public }(n=23)\end{array}$ & $\begin{array}{l}\text { Sometimes cross- } \\
\text { dressing }(n=10)\end{array}$ & $\begin{array}{l}\text { Always cross-dressing } \\
\qquad(n=27)\end{array}$ & $P$ \\
\hline Age (year, mean \pm s.d.) & 60 & $30.5 \pm 17.5$ & $27.7 \pm 18.5$ & $35.8 \pm 14.3$ & $30.9 \pm 17.7$ & 0.55 \\
\hline Initial age of transgender feelings (year, mean \pm s.d.) & 60 & $9.1 \pm 5.4$ & $9.9 \pm 6.1$ & $8.3 \pm 6.8$ & $8.7 \pm 4.3$ & 0.45 \\
\hline Use of cross-sex hormones ( $n, \%)$ & 60 & $44(73 \%)$ & $12(52 \%)$ & $7(70 \%)$ & $25(93 \%)$ & 0.001 \\
\hline Hormones advised or prescribed by $(n, \%)$ & 44 & & & & & \\
\hline Doctor or pharmacist & & $2(5 \%)$ & $1(8 \%)$ & $0(0 \%)$ & $1(4 \%)$ & 0.63 \\
\hline Happy with hormones ( $n, \%)$ & 44 & $12(27 \%)$ & $4(33 \%)$ & $1(14 \%)$ & $7(28 \%)$ & 0.83 \\
\hline Side effects of hormones $(n, \%)$ & 44 & $17(39 \%)$ & $5(42 \%)$ & $4(57 \%)$ & $8(32 \%)$ & 0.47 \\
\hline Period using hormones (year, mean \pm s.d.) & 44 & $9.7 \pm 6.1$ & $8.6 \pm 3.8$ & $9.6 \pm 7.9$ & $10.2 \pm 6.7$ & 0.48 \\
\hline Wanting surgery $(n, \%)$ & 60 & & & & & \\
\hline Yes & & $15(25 \%)$ & $0(0 \%)$ & $0(0 \%)$ & $15(56 \%)$ & $<0.001$ \\
\hline Maybe or not & & $45(75 \%)$ & $23(100 \%)$ & $10(100 \%)$ & $12(44 \%)$ & \\
\hline Yes & & $50(83 \%)$ & $20(87 \%)$ & $7(70 \%)$ & $23(85 \%)$ & 0.90 \\
\hline Reasonable well to no acceptance & & $10(17 \%)$ & $3(13 \%)$ & $3(30 \%)$ & $4(15 \%)$ & \\
\hline Acceptance by parents ( $n, \%)$ & 60 & & & & & \\
\hline Yes & & $51(85 \%)$ & $19(83 \%)$ & $7(70 \%)$ & $25(93 \%)$ & 0.31 \\
\hline Reasonable well to no acceptance & & $9(15 \%)$ & $4(17 \%)$ & $3(30 \%)$ & $2(7 \%)$ & \\
\hline Acceptance by brothers/sisters ( $n, \%$ ) & 45 & & & & & \\
\hline Yes & & $40(89 \%)$ & $16(89 \%)$ & $6(75 \%)$ & $18(95 \%)$ & 0.57 \\
\hline Reasonable well to no acceptance & & $5(11 \%)$ & $2(11 \%)$ & $2(25 \%)$ & $1(5 \%)$ & \\
\hline More transgender persons in family $(n, \%)$ & 60 & $11(18 \%)$ & $4(17 \%)$ & $2(20 \%)$ & $5(19 \%)$ & 0.92 \\
\hline Gay persons in family $(n, \%)$ & 60 & $19(32 \%)$ & $6(26 \%)$ & $5(50 \%)$ & $8(30 \%)$ & 0.83 \\
\hline
\end{tabular}

$P$ is obtained by chi-squared test or analysis of variance (for trend over the three groups, when appropriate). Some numbers and percentages do not total 60 as 16 kathoeys did not use hormones and 15 kathoeys did not have brothers or sisters.

for prolonged periods $(9.7 \pm 6.1$ years $)$. The most commonly used were oral contraceptives available in Thailand, while four individuals also used the antiandrogen cyproterone acetate in addition to two contraceptive pills per day. One person used an oral contraceptive containing cyproterone acetate. Three people used injectable oestrogens and were overdosing ('stacking') oestrogen preparations. One used finasteride as the sole drug. Oral contraceptives were taken one tablet per day by 16 subjects, two per day by seven and three per day by 13. Oral contraceptives contain a progestin-type of drug combined mostly with ethinyl estradiol and sometimes the oestrogen mestranol. Taken in doses of two to three tablets per day, the daily intake of ethinyl estradiol was between $30 \mu \mathrm{g}$ and $150 \mu \mathrm{g}$. In total, more than $50 \%$ of hormone users were taking an overdose of oestrogen. It is of note that the ethinyl estradiol per molecule is 3-6 times more biopotent than $17 \beta$-estradiol. ${ }^{18}$ Therefore, overdosing should be regarded in terms of not only the dose of oestrogen but also the biopotency of the oestrogen and the resulting potential of side effects. In the loosely connected network of kathoeys, some were recognized as having greater knowledge than others and were regarded as sources of information.

Monthly expenditure on hormones ranged between 150 and 450 Baht (US\$ 5-15). Approximately 35\% of subjects knew doctors and pharmacists who were knowledgeable on the use of hormones in the kathoey people, but remarkably, only about $5 \%$ obtained their hormones directly from a pharmacy. For 70\%, the main source of information on hormones was their peer group, who provided hormones, bought from pharmacies, to about $96 \%$ of the hormone users.
Side effects had been noted by $39 \%$ of the interviewees themselves, but a larger percentage (75\%) had knowledge of side effects among peers. Feared somatic side effects were an increase in appetite and subsequent weight gain, but this had not occurred in this group because of anticipatory dietary restrictions. There was little or no awareness of other potential somatic side effects.

It should be noted that our data on side effects rely on the personal accounts of the test subjects obtained outside of a clinical setting. There were no physical or laboratory examinations to assess/verify side effects.

When asked about their expectations from using hormones, all subjects desired smooth, soft skin with no secondary male hair growth, a lack of acne and female-type development of breasts and nipples as well as body fat distribution. Almost all subjects realized, from experiences of their peers, that the hormone-induced female type development of breasts, nipples and body fat distribution, might be less than desired. About $27 \%$ were satisfied with the biological effects of hormones, while $7 \%$ were dissatisfied. For the majority of the interviewees, the degree of satisfaction lay somewhere in between satisfied and dissatisfied. The decisions on the type of hormone treatment used were determined by trial and error of several brands of oral contraceptives, based on the recommendations of peers and price. Most subjects $(67 \%)$ could not recall psychological side effects, including changes in mental well-being since commencing the use of hormones. The somatic side effects mentioned were a feared increase in appetite and subsequent weight gain. There was little or no awareness of other potential somatic side effects of hormone use, such as changes in blood 
coagulation and lipids or hyperprolactinemia, and similarly, few were aware that laboratory tests to diagnose these side effects might be desirable. The desire to undergo surgery was correlated with the permanence of living in the female role, but this aspiration was certainly not shared by all the interviewees (Table 1 ).

\section{Functional health and mental well-being}

Self-acceptance was high or reasonable (83\%) compared to no acceptance $(17 \%)$, and this parameter was not related to the permanence of cross-dressing. Acceptance by parents and siblings was also relatively high ( $85 \%$ and $89 \%$, respectively).

There was a high incidence of other transgendered (18\%) and homosexual $(32 \%)$ people in the families (related by blood) of the persons questioned (Table 1).

The results of the questionnaire about optimism, the SF-36 and the questionnaire about social functioning are summarized in Tables 2 and 3. The social functioning, quality of life and emotional well-being of the kathoey subjects in relation to the degree of permanence of cross-dressing are presented in Table 2. There were no significant differences in these scores among the groups according to the permanence of cross-dressing. We found that hormone use was largely unrelated to functional health and mental well-being, although there was a nonsignificant trend towards somewhat better mental health and vitality in participants not using cross-sex hormones (Table 4).

Table 3 presents the independent effects of poor acceptance on general well-being and functioning. The impression was given that acceptance by oneself or one's parents did not affect social functioning, quality of life and mental well-being, but acceptance by siblings seemed to have a significant effect on social functioning and general mental health. Main stressors seemed to be the physical rather than the social factors, as shown by the interpretation of the strength of all correlation coefficients among the different scales of functional health and mental well-being (data not shown).

\section{DISCUSSION}

This study was a feasibility study to explore whether we could recruit a meaningful sample of kathoeys willing to answer our questions. The goal was to provide insights into cross-sex hormone use in a convenience sample of kathoeys in Chiang Mai, Thailand, and into their (self)acceptance and state of well-being in a country regarded as rather accepting of kathoeys. ${ }^{4,11,12}$ Because of the exploratory nature of the study, the results are preliminary.

\section{Hormone use}

In this sample of people who self-identify as kathoeys and who live as females on either a part-time or full-time basis, hormones were used by 44 of the 60 subjects, and a clear relationship existed with the degree of permanence of living as a woman. In Thailand, there are no real financial barriers to see a physician for guidance on hormone use, but among the participants, there was little confidence that the medical establishment truly had the necessary expertise on the matter of hormonal treatment of kathoeys. Moreover, it was the study participants' view that they as kathoeys would encounter little sympathy for their needs. Almost all the interviewees obtained directly from pharmacies (no prescriptions are needed in Thailand) or from peers who had bought them at pharmacies. They mainly relied on information from peers regarding the use of the hormones. Certain specific peers were considered more knowledgeable than others, and these individuals served as the primary source of information.

Overdosing on hormones, defined as use of a higher dose than necessary to achieve the aims of the drugs, was reported by about $50 \%$ of the sample. Side effects were mentioned by $39 \%$, and the knowledge of side effects in others, by $75 \%$, but these could not be specified in detail, except for an increase in appetite.

The most commonly used sex steroids in transgendered people in Thailand are oral contraceptives, which are widely obtainable and affordable. If the oral contraceptives are taken in doses of two to three tablets per day, the risk of venous thrombosis ${ }^{19}$ or cardiovascular death may be increased. ${ }^{7}$

We found that hormone use was largely unrelated to functional health or mental well-being, although there was a trend towards somewhat better mental health and vitality in participants not using crosssex hormones (Table 4).

\section{Transgendered or gay siblings}

There was a high prevalence of transgendered (18\%) and homosexual $(32 \%)$ people in the families of the persons tested, which has also been noted in earlier work in Thailand ${ }^{3}$ and, to a lesser degree, elsewhere. ${ }^{20}$ These findings are difficult to interpret in

Table 2 Functional health and mental well-being of a sample of kathoeys in Thailand according to the patterns of cross-dressing. Data are expressed as mean \pm s.d.

\begin{tabular}{|c|c|c|c|c|c|}
\hline & All subjects $(\mathrm{n}=60)$ & $\begin{array}{c}\text { No cross-dressing in } \\
\text { public }(\mathrm{n}=23)\end{array}$ & $\begin{array}{l}\text { Sometimes cross- } \\
\text { dressing }(\mathrm{n}=10)\end{array}$ & $\begin{array}{l}\text { Always cross-dressing } \\
\qquad(n=27)\end{array}$ & P-value \\
\hline Dispositional optimism & $12.9 \pm 2.3$ & $13.3 \pm 2.6$ & $12.7 \pm 2.2$ & $12.6 \pm 2.2$ & 0.33 \\
\hline Social Functioning Questionnaire & $7.0 \pm 2.9$ & $6.8 \pm 2.7$ & $7.5 \pm 4.9$ & $7.0 \pm 2.3$ & 0.85 \\
\hline \multicolumn{6}{|l|}{ Short Form 36 (SF-36) subscales: } \\
\hline Bodily pain & $63 \pm 31$ & $66 \pm 28$ & $70 \pm 36$ & $59 \pm 33$ & 0.39 \\
\hline Role-physical & $77 \pm 32$ & $75 \pm 32$ & $68 \pm 41$ & $82 \pm 28$ & 0.40 \\
\hline Physical functioning & $76 \pm 18$ & $80 \pm 13$ & $65 \pm 26$ & $78 \pm 18$ & 0.75 \\
\hline Social functioning & $71 \pm 26$ & $78 \pm 24$ & $63 \pm 35$ & $68 \pm 23$ & 0.17 \\
\hline Mental health & $65 \pm 17$ & $67 \pm 13$ & $63 \pm 15$ & $63 \pm 20$ & 0.47 \\
\hline Role-emotional & $72 \pm 37$ & $71 \pm 38$ & $70 \pm 40$ & $74 \pm 37$ & 0.77 \\
\hline Vitality & $64 \pm 14$ & $65 \pm 12$ & $64 \pm 14$ & $63 \pm 16$ & 0.61 \\
\hline General health & $60 \pm 19$ & $59 \pm 18$ & $60 \pm 13$ & $61 \pm 23$ & 0.83 \\
\hline
\end{tabular}

$P$ is obtained by analysis of variance for trend over the three groups or $t$-test for independent samples.

Higher scores on the dispositional optimism scale, Social Functioning Questionnaire (SFQ) and the Short Form Health Survey 36 (SF-36) indicate, respectively, higher optimism, worse social functioning and better quality of life. 
Table 3 Independent effects of poor acceptance on functional health and mental well-being of a sample of kathoeys in Thailand

\begin{tabular}{|c|c|c|c|}
\hline & Acceptance of oneself & Acceptance by parents & Acceptance by brothers/sisters \\
\hline Dispositional optimism & $0.03(P=0.87)$ & $-0.12(P=0.55)$ & $-0.05(P=0.78)$ \\
\hline Social Functioning Questionnaire & $0.03(P=0.86)$ & $0.24(P=0.20)$ & $0.28(P=0.11)$ \\
\hline \multicolumn{4}{|l|}{ Short Form 36 (SF-36) subscales: } \\
\hline Role-physical & $0.02(P=0.91)$ & $-0.22(P=0.26)$ & $-0.11(P=0.54)$ \\
\hline Physical functioning & $0.02(P=0.90)$ & $-0.20(P=0.31)$ & $-0.02(P=0.93)$ \\
\hline Social functioning & $-0.01(P=0.93)$ & $0.00(P=0.98)$ & $-0.47(P=0.008)$ \\
\hline Vitality & $0.14(P=0.38)$ & $-0.20(P=0.32)$ & $-0.08(P=0.65)$ \\
\hline General health & $0.20(P=0.21)$ & $0.00(P=0.98)$ & $-0.23(P=0.22)$ \\
\hline
\end{tabular}

Beta-coefficients and $P$ are obtained by multivariable regression analysis adjusted for age. Higher scores on the dispositional optimism scale, Social Functioning Questionnaire (SFQ) and the Short Form Health Survey 36 (SF-36) indicate, respectively, higher optimism, worse social functioning and better quality of life. The data shown in bold are statistically significant values.

view of the small sample; they could point to a genetic element in the aetiology of transgenderism ${ }^{21,22}$ but also to psycho-social factors. $^{23,24}$

\section{Functional health and mental well-being}

Transgendered people desire to live as members of the opposite natal sex, and adopting that role in the public arena adds to their mental well-being. ${ }^{23}$ Kathoeys in Thailand enjoy tolerance in society to a greater degree than in most other parts of the world. ${ }^{3,12}$ Kathoeys in Thailand are employed in a wide range of jobs including employment by the government. Many universities have a policy of kathoey acceptance in place. While we did not measure societal tolerance, the benign social climate was probably reflected in our findings. Negative scores on mental well-being in this cohort seemed for the most part influenced not by social factors but rather by the subjects' physical discomfort/limitations. Subjective well-being seemed to be more strongly determined by the less subjective measures of physical health (i.e., role limitations due to physical health problems, bodily pain and physical functioning) than by their permanence in the transgendered role and the acceptance thereof.

\section{Limitations of the study}

Our study has a number of limitations. The sample was a convenience sample consisting of exclusively self-identified kathoeys, who voluntarily participated and received modest financial compensation. Inclusion into the study was based on belonging to a group of people known to one another by social networks, not a random sampling. The educational level of the participants was above average. The latter may have had implications for the LOTR. There is evidence that higher education is correlated with higher dispositional optimism; ${ }^{14}$ however, education was not formally assessed in our study and thus could be a potential confounding variable.

The questionnaires used in this study have not been validated for use in the Thai language. To assure comprehension, the questions were orally presented by the interviewer, who asserted that the questions were understood and answered. We acknowledge that differences in the mean scores in comparison to findings from other studies could be due to this methodological issue instead of representing true differences. Nevertheless, we believe that the results have adequate internal validity, as comparisons were only made within the group of participants who all completed the same questionnaire using the same methodology.

It should be noted that a representative research population of transgendered subjects is not easily accessible. Our study was a feasibility study. It turned out that it was relatively easy to access the population that we studied. With this knowledge, larger and betterdesigned interdisciplinary studies may be conducted.

Table 4 Functional health and mental well-being of a sample of kathoeys in Thailand according to the use of cross-sex hormones. Data are expressed as mean \pm s.d.

\begin{tabular}{|c|c|c|c|c|}
\hline & All subjects $(\mathrm{n}=60)$ & $\begin{array}{l}\text { Use of cross-sex hormones } \\
\qquad(\mathrm{n}=44)\end{array}$ & $\begin{array}{c}\text { No use of cross-sex } \\
\text { hormones }(\mathrm{n}=16)\end{array}$ & P-value \\
\hline Dispositional optimism & $12.9 \pm 2.3$ & $12.8 \pm 2.5$ & $13.2 \pm 2.1$ & 0.53 \\
\hline Social Functioning Questionnaire & $7.0 \pm 2.9$ & $7.3 \pm 2.5$ & $6.3 \pm 4.0$ & 0.25 \\
\hline \multicolumn{5}{|l|}{ Short Form 36 (SF-36) subscales: } \\
\hline Bodily pain & $63 \pm 31$ & $61 \pm 32$ & $69 \pm 28$ & 0.42 \\
\hline Role-physical & $77 \pm 32$ & $76 \pm 34$ & $81 \pm 25$ & 0.55 \\
\hline Physical functioning & $76 \pm 18$ & $75 \pm 19$ & $78 \pm 17$ & 0.62 \\
\hline Social functioning & $71 \pm 26$ & $72 \pm 23$ & $69 \pm 34$ & 0.68 \\
\hline Mental health & $65 \pm 17$ & $62 \pm 16$ & $71 \pm 17$ & 0.06 \\
\hline Role-emotional & $72 \pm 37$ & $68 \pm 39$ & $83 \pm 32$ & 0.17 \\
\hline Vitality & $64 \pm 14$ & $62 \pm 14$ & $69 \pm 12$ & 0.08 \\
\hline General health & $60 \pm 19$ & $59 \pm 20$ & $64 \pm 18$ & 0.33 \\
\hline
\end{tabular}

$P$ is obtained by analysis of variance for trend over the three groups or $t$-test for independent samples.

Higher scores on the dispositional optimism scale, Social Functioning Questionnaire (SFQ) and the Short Form Health Survey 36 (SF-36) indicate, respectively, higher optimism, worse social functioning and better quality of life. 


\section{AUTHOR CONTRIBUTIONS}

LJG conceived and codesigned the study, and took main responsibility for writing the paper. TS performed the interviews and prepared statistical analysis. EJG codesigned the study, performed the statistical analysis and contributed to writing the paper.

\section{COMPETING FINANCIAL INTERESTS}

The authors declare no conflicts of interest.

\section{ACKNOWLEDGMENTS}

This research was financed by the Stichting Reproductieve Geneeskunde, Amsterdam, The Netherlands.

1 Gooren LJ. Clinical practice. Care of transsexual persons. N Eng/ J Med 2011; 364: 1251-7.

2 ten Brummelhuis $\mathrm{H}$. Transformations of transgender. The case of the Thai Kathoey. J Gay Lesb Soc Serv 1999; 9: 121-39.

3 Winter S. Thai transgenders in focus: demographics, transitions and identities. Int $J$ Transgenderism 2006; 9: 15-29.

4 Winter S, Udomsak N. Male, female and transgender: stereotypes and self in Thailand Int J Transgenderism. http://www.wpath.org/journal/www.iiav.nl/ezines/web/IJT/9703/numbers/symposion/ijtvo06no01_04.htm 2002.

5 Hembree WC, Cohen-Kettenis P, Delemarre-van de Waal HA, Gooren LJ, Meyer WJ 3rd et al. Endocrine treatment of transsexual persons: an Endocrine Society clinical practice guideline. J Clin Endocrinol Metab 2009; 94: 3132-54.

6 Gooren LJ, Giltay EJ, Bunck MC. Long-term treatment of transsexuals with cross-sex hormones: extensive personal experience. J Clin Endocrinol Metab2008; 93: 19-25.

7 Asscheman H, Giltay EJ, Megens JA, de Ronde WP, van Trotsenburg MA et al. A longterm follow-up study of mortality in transsexuals receiving treatment with cross-sex hormones. Eur J Endocrinol 2011; 164: 635-42.

8 Sanchez NF, Sanchez JP, Danoff A. Health care utilization, barriers to care, and hormone usage among male-to-female transgender persons in New York City. Am J Public Health 2009; 99: 713-9.

9 Guadamuz TE, Wimonsate W, Varangrat A, Phanuphak P, Jommaroeng R et al. HIV prevalence, risk behavior, hormone use and surgical history among transgender persons in Thailand. AIDS Behav 2011; 15: 650-8.
10 Chokrungvaranont $\mathrm{P}$, Tiewtranon $\mathrm{P}$. Sex reassignment surgery in Thailand. J Med Assoc Thai 2004; 87: 1402-8.

11 Sood N. Access to sexual health and rights. A study of law and policy in 12 Asian countries. In: Pacific Resource and Research Centre for Women. http://www. asylumlaw.org/docs/sexualminorities/TransPeopleAccessSexualHealth_Rights0410. pdf 2009.

12 Winter S. Thai transgenders in focus: their beliefs about attitudes towards and origins of transgender. Int J Transgenderism 2006; 9: 47-62.

13 Scheier MF, Carver CS, Bridges MW. Distinguishing optimism from neuroticism (and trait anxiety, self-mastery, and self-esteem): a reevaluation of the Life Orientation Test. J Pers Soc Psychol 1994; 67: 1063-78.

14 Glaesmer H, Rief W, Martin A, Mewes R, Brahler E et al. Psychometric properties and population-based norms of the Life Orientation Test Revised (LOT-R). Br J Health Psychol 2012; 17: 432-45.

15 Tyrer P, Nur U, Crawford M, Karlsen S, McLean C et al. The Social Functioning Questionnaire: a rapid and robust measure of perceived functioning. Int J Soc Psychiatry 2005; 51: 265-75.

16 Ware J, Snow K, Kosinski M, Gandek B. SF-36 Health Survey Manual and Interpretation Guide. Boston, MA: New England Medical Center, The Health Institute; 1993.

17 Hopman WM, Towheed T, Anastassiades T, Tenenhouse A, Poliquin S et al. Canadian normative data for the SF-36 health survey. Canadian Multicentre Osteoporosis Study Research Group. CMAJ 2000; 163: 265-71.

18 Dickson RB, Eisenfeld AJ. 17 Alpha-ethinyl estradiol is more potent than estradiol in receptor interactions with isolated hepatic parenchymal cells. Endocrinology 1981; 108: 1511-8.

19 Toorians AW, Thomassen MC, Zweegman S, Magdeleyns EJ, Tans G et al. Venous thrombosis and changes of hemostatic variables during cross-sex hormone treatment in transsexual people. J Clin Endocrinol Metab 2003; 88 5723-9.

20 Gooren L. The biology of human psychosexual differentiation. Horm Behav 2006; 50: 589-601.

21 Bentz EK, Hefler LA, Kaufmann U, Huber JC, Kolbus A et al. A polymorphism of the CYP17 gene related to sex steroid metabolism is associated with female-to-male but not male-to-female transsexualism. Fertil Steril 2008; 90: 56-9.

22 Hare L, Bernard P, Sanchez FJ, Baird PN, Vilain E et al. Androgen receptor repeat length polymorphism associated with male-to-female transsexualism. Biol Psychiatry 2009; 65: 93-6.

23 Cohen-Kettenis PT, Gooren LJ. Transsexualism: a review of etiology, diagnosis and treatment. J Psychosom Res 1999; 46: 315-33.

24 Zucker KJ. Gender identity development and issues. Child Adolesc Psychiatr Clin N Am 2004; 13: 551-68, vii. 